\title{
ERRATUM
}

\section{CK2 mediates phosphorylation and ubiquitin-mediated degradation of the PML tumor suppressor}

\author{
P. P. Scaglioni $\cdot$ T. M. Yung $\cdot$ S. Choi $\cdot$ C. Baldini $\cdot$ \\ G. Konstantinidou · P. P. Pandolfi
}

Published online: 6 May 2009

(C) Springer Science+Business Media, LLC. 2009

Erratum to: Mol Cell Biochem (2008) 316:149-154

DOI: 10.1007/s11010-008-9812-7

In the paper, the name of the third author is given as S. C. Choi. Dr. Sooyeon Choi does not have a middle initial. Her correct name should read "S. Choi".

Everything else in the paper remains correct.

The online version of the original article can be found under doi: 10.1007/s11010-008-9812-7.

P. P. Scaglioni $(\bowtie) \cdot$ S. Choi · C. Baldini · G. Konstantinidou Division of Hematology-Oncology, University of Texas Southwestern Medical Center, Dallas, TX 75390-8852, USA

e-mail: pier.scaglioni@utsouthwestern.edu

T. M. Yung

Cancer Biology and Genetics Program, Sloan-Kettering Institute, Memorial Sloan-Kettering Cancer Center, New York,

NY 10021, USA

P. P. Pandolfi

Cancer Genetics Program, Beth Israel Deaconess Cancer Center, Harvard Medical School, Boston, MA 02215, USA

P. P. Pandolfi

Department of Medicine, Beth Israel Deaconess Medical Center, Harvard Medical School, Boston, MA 02215, USA 